\title{
Labour duration and timing of interventions in women planning vaginal birth after caesarean section
}

Susanne Grylka-Baeschlin, Antje Petersen, André Karch, Mechthild M. Gross

Susanne Grylka-Baeschlin, midwife, BSc, MSc, Midwifery Research and Education Unit, Hannover Medical School, Carl-Neuberg-Str. 1, D-30625 Hannover, Germany, Grylka-Baeschlin.Susanne@mh-hannover.de, Tel. +49 511532 6985, Fax +49 511 5326191 and PhD Programme „Epidemiology“, Braunschweig-Hannover

Antje Petersen, Dr. MD, Midwifery Research and Education Unit, Hannover Medical School, Carl-Neuberg-Str. 1, D-30625 Hannover Germany, Petersen.Antje@mhhannover.de, Tel. +49511532 6116, Fax +495115326191

André Karch, MSc, MD, Department of Epidemiology, Helmholtz Centre for Infection Research (HZI), Inhoffenstr. 7, D-38124 Braunschweig Germany.

Andre.Karch@helmholtz-hzi.de, Tel. +4953161813113

Mechthild M. Gross, RM, RN, BSc, MSc, Prof. Dr., Midwifery Research and Education Unit, Hannover Medical School, Carl-Neuberg-Str. 1, D-30625 Hannover Germany, Gross.Mechthild@mh-hannover.de, Tel. +49511532 6116, Fax +49 511 5326191

Corresponding author: Susanne Grylka-Baeschlin, midwife, BSc, MSc, PhD student, Midwifery Research and Education Unit, Hannover Medical School, CarlNeuberg-Str. 1, D-30625 Hannover, Germany, Grylka-Baeschlin.Susanne@mhhannover.de, Tel. +49 511532 6985, Fax +49 5115326191 and PhD Programme „Epidemiology“, Braunschweig-Hannover 


\section{Highlights}

- Multiparous women with first pVBAC had shorter second stage of labour as primiparae

- Oxytocin was administered less often with pVBAC than in primiparae

- Timing of interventions and SROM of pVBAC were similar to primiparae

- Vaginal birth rates of pVBAC were lower compared to primiparae and other multiparae

- Labour characteristics differed significantly from those of other multiparous women 


\section{Abstract}

Objective: Understanding the labour characteristics of women attempting vaginal birth after caesarean (VBAC) may suggest how to improve intrapartum management and may enhance success rates. Promoting VBAC is a relevant factor in decreasing overall caesarean section (c-section) rates. However, the labour processes of women attempting VBAC are not well investigated. The aim of this paper is to compare multiparae planning a first VBAC (pVBAC) with primiparae and with multiparae planning a second vaginal birth, all starting to give birth vaginally, with regard to: a) perinatal characteristics, b) the timing of intrapartal spontaneous rupture of membranes (SROM) and of interventions, and c) labour duration, with respect to the first and second stages.

Setting: Cohort study of women planning vaginal birth in 47 obstetric units in Lower Saxony, Germany.

Participants: 1,897 primiparae, 211 multiparae with one previous c-section and 1,149 multiparae with one previous vaginal birth.

Measurements: Secondary analysis of data from an existing cohort study. KaplanMeier estimates, log rank test, Wilcoxon test and shared frailty Cox regression models including time-varying covariates were used to compare the timing of interventions and labour duration between the subsamples. Analyses were done with the statistics programme Stata 13.

Findings: Perinatal and labour characteristics of multiparae with pVBAC mainly resembled those of primiparae and differed from those of multiparae planning a second vaginal birth. However, compared to primiparae, multiparae with pVBAC received oxytocin less often ( 48.82 vs $56.95 \%, p=0.024$ ) and gave birth vaginally significantly less often ( 69.19 vs $83.40 \%, p<0.001)$. The timing of intrapartal SROM (2.67 vs 3.42 hrs, $p=0.112$ ) and of interventions (amniotomy: 5.50 vs $5.83 \mathrm{hrs,}$ $p=0.198$; oxytocin: 5.75 vs 6.00 hrs, $p=0.596$; epidural: 4.00 vs 4.67 hrs, $p=0.416$; opioids: 3.83 vs $3.78, p=0.851$ ) was similar to that in primiparae although timings of all interventions but not of SROM differed significantly from that in multiparae with second vaginal birth (SROM: 2.67 vs $2.67 \mathrm{hrs}, \mathrm{p}=0.481$; amniotomy: 5.50 vs $3.93 \mathrm{hrs}$, $p<0.001$; oxytocin: 5.75 vs 4.25 hrs, $p<0.001$; epidural: 4.00 vs 3.50 hrs, $p=0.009$; 3.83 vs. $2.75 \mathrm{hrs}, p=0.026$ ). Overall and first-stage labour duration were comparable to primiparae (overall labour duration: 8.83 vs $8.57 \mathrm{hrs}, \mathrm{HR}=0.998,95 \% \mathrm{Cl}=0.830$ - 
1.201, $\mathrm{p}=0.987$; first stage: 6.00 vs $6.53 \mathrm{hrs}, \mathrm{HR}=0.940,95 \% \mathrm{Cl}=0.789-1.121$, $\mathrm{p}=0.492$ ) but significantly longer than in other multiparae (overall labour duration:

8.83 vs $4.63 \mathrm{hrs}, \mathrm{HR}=0.319,95 \% \mathrm{Cl}=0.265-0.385, \mathrm{p}<0.001$; first stage: 6.00 vs 4.17 hrs, $\mathrm{HR}=0.429,95 \% \mathrm{Cl}=0.359-0.512, \mathrm{p}<0.001)$. However, the second stage of labour was significantly shorter in multiparae with pVBAC than in primiparae (0.55 vs 0.77 hrs, $\mathrm{HR}=1.341,95 \% \mathrm{Cl}=1.049-1.714, \mathrm{p}=0.019$ ), but longer than in multiparae with second vaginal birth ( 0.55 vs 0.22 hrs, $\mathrm{HR}=0.334,95 \% \mathrm{Cl}=0.262-0.426, \mathrm{p}<0.001$ ). Key conclusion: Labour patterns of multiparous women planning a VBAC differ from those of primiparae and other multiparous women. Multiparae with pVBAC should be considered as a distinct group of parturients.

Implication for practice: Expectations regarding labour progression for multiparae with first pVBAC should be similar to those for primiparae. However, the chance that the second stage of labour might be shorter than in primiparae is relevant and motivating information for pregnant women with a previous c-section in deciding the planned mode of birth.

Keywords: trial of labour after caesarean, secundiparae, first stage labour duration, second stage labour duration, survival analysis, Cox regression 


\section{Introduction}

Understanding labour characteristics of women planning vaginal birth after caesarean section (VBAC) may suggest how to improve intrapartum management. This is relevant for achieving a successful and safe VBAC (Scott 2014).Promoting VBAC is a relevant factor in decreasing overall caesarean section (c-section) rates (Cheng et al. 2011, Sabol et al. 2015) and supports efforts to avoid multiple c-sections with increasingly adverse outcomes (Marshall et al. 2011). Rising c-section rates are of international concern and cannot be explained by risk factors such as age and parity (Euro-Peristat 2013, ACOG et al. 2014).

The absolute risks for women planning a VBAC and for their children are low (Landon et al. 2004, Nair et al. 2015). Maternal mortality is three times higher with elective repeat c-section (ERSC) than with planned VBAC (pVBAC) ( 0.013 vs $0.004 \%$, Guise et al. 2010). The risk of infant loss, however, is higher for VBAC than for elective repeat c-section (ERCS) ( 0.13 vs $0.05 \%$ ) but comparable to that for women giving birth to their first child (Smith et al. 2002). Uterine rupture is more frequent with pVBAC than with ERCS (Guise et al. 2010). The risk of uterine rupture is lower with spontaneous labour than with induced labour (Dekker at al. 2010, Palatnik \& Grobman 2015). Hospital stays have been found to be shorter, satisfaction with the mode of birth higher, recovery after birth better, quality of life as determined by physical health higher, breast-feeding initiation rates higher and the costs lower with pVBAC than with ERCS (Guise et al. 2010, Shorten \& Shorten 2012, Kealy et al. 2010, Karlström et al. 2013, Fawsitt et al. 2013, Regan et al. 2013, Prick et al. 2015). With conscientious intrapartum management there is a high probability of a safe and successful vaginal birth outcome meaning that caution is needed with induction and augmentation of labour to avoid overstimulation of contractions and that a thorough surveillance regarding signs of uterine rupture is necessary (RCOG 2007, Scott 2014). Several studies found that $60-85 \%$ of women planning VBAC did indeed give birth vaginally (Balachandran et al. 2014, Knight et al. 2014, Tessmer-Tuck et al. 2014), including even women at high risk (Regan et al. 2015); it is therefore asserted that women should be informed about the high likelihood of a successful outcome (King et al. 2015). 
Uterine activity differs according to parity (Arulkumaran et al. 1984). This has a significant impact on labour duration, which is shorter with the second baby than with the first one (Albers 1996, Vahratian et al. 2006, Zhang et al. 2010, Petersen et al. 2011). So far, no other study investigating timing of interventions was found. In the overall sample of the same cohort study including 3,963 participants, amniotomy, oxytocin and epidural were performed slightly earlier in multiparae than in primiparae $(X)$. Consequently the median intervention-free time span after onset of labour has been found to be shorter for multiparae than for primiparae $(X)$ and the sequence of interventions differs $(X)$. There is less evidence on the labour patterns of women with a previous c-section. Graseck et al. (2012) found no difference in cervical dilatation between women with pVBAC and women without a previous c-section. Multiparous women who had had a previous c-section because of dystocia were found to have a similar or longer labour duration than primiparous women (Harlass \& Duff 1990). Grantz et al. (2015) found that labour progression from 4 to $10 \mathrm{~cm}$ cervical dilatation was slower in multiparae with first VBAC where labour was induced than in primiparae. Faranesh \& Salim (2011) by contrast found shorter active phases of the first stage and shorter second stages of labour for multiparous women with VBAC as compared to primiparae. Multiparous women with second vaginal births by contrast had shorter active phases and second stages than multiparae with first VBAC (Faranesh \& Salim 2011). The frequency and timing of interventions in the cases of women with pVBAC have however not been investigated in previous studies.

The aim of this paper is to compare multiparous women planning a first VBAC with primiparous women and multiparous women planning a second vaginal birth in respect of:

a) baseline and perinatal characteristics

b) the timing of intrapartal SROM, amniotomy, oxytocin, epidural and opioid administration

c) the overall duration of labour and the durations of the first and second stages of labour. 


\section{Methods}

\section{Study design and setting}

This study is based on a secondary analysis of the ProGeb dataset, which was derived from a cohort study undertaken between April and October 2005 in 47 of the 96 maternity units in Lower Saxony with birth rates ranging from 500 to 2,000 births per year (Gross et al. 2007, Gross et al. 2009, Petersen et al. 2011, Petersen et al. 2013a, Petersen et al. 2013b, Gross et al. 2014). Women were eligible for this study if they were expecting a singleton in vertex presentation, were over 34 weeks of gestation and had started to give birth vaginally after onset of labour assessed by the midwife in terms of regular or irregular contractions associated with cervical dilatation (Gross et al. 2009). Parturients over 34 weeks were included because recommendations in German guidelines consider them together with women at term as one target group (DGGG 2006, DGGG 2010b, DGGG 2012). Midwives in the current study defined onset of labour as the moment when labour started to progress without being tied to exact centimetres of dilatation. This approach was chosen, because there is no homogenous definition which addresses the complexity of onset of labour appropriately (Hanley et al., submitted for publication). In general, German perinatal statistics count labour duration from the onset of regular contraction (Aqua 2015).

Prospective data was collected from 47 hospitals, and also in addition retrospective data from the medical records of seven of these hospitals relating to all eligible women for whom prospective data was lacking (Petersen et al. 2011). The prospective sample consisted of 1,169 participants (29.50\%), the retrospective one of 2,794 participants $(70.50 \%)$, giving a total of 3,963 women. A theoretical figure of $n=$ 25,028 births in Lower Saxony was calculated for the six months of data collection (Petersen et al. 2011). The whole study sample therefore comprised of about $16 \%$ of eligible parturients giving birth during the six months period in the federal state. Within the study population, there were 302 women with a history of c-section who were planning a VBAC; 211 of these were multiparous women expecting their second child and planning a VBAC.

Multiparous women ( $n=724)$ giving birth for the third time or more were excluded from the analysis because they did not meet the inclusion criteria for this secondary 
analysis. Thus the study population investigated consisted of three subsamples: the 211 multiparous women with planned first VBAC, in the following called "multiparae with pVBAC" for short (6.5\% of the study population), who were compared with 1,879 primiparous women ("primiparae", 58.01\%) and 1,149 multiparous women planning their second vaginal birth ("other multiparae", 35.47\%). Inequalities of the sample sizes could be accepted because these differences correspond to the natural and random mixing of birthing women in the study sample, do not affect statistical analyses and because matching the subgroups would have led to sources of selection bias.

The ProGeb study received ethical approval from the Ethics Committee of Hannover Medical School and from the Ethics Committee of the Chamber of Physicians for all public hospitals in Lower Saxony.

\section{Data preparation}

Women not having received either amniotomy, oxytocin, epidural analgesia or opioids between onset of labour and birth were classified as having had "No intervention during labour". The intervention-free time span was calculated as the duration between onset of labour and the first of any one of these four interventions.

It is unlikely that any events or interventions would occur simultaneously with onset of labour or birth, and for the analysis of Kaplan-Meier estimates the Stata software excludes durations of zero minutes. Since measurements were recorded in minutes, any such events or interventions were therefore deemed to have occurred one minute after onset of labour or one minute before birth.

\section{Data analysis}

Descriptive analysis was carried out on the baseline characteristics and on the frequencies of interventions and of spontaneous rupture of the membranes. The comparisons of the subsamples, namely multiparae with first pVBAC, primiparae and multiparae with a second vaginal birth, were computed using chi-squared tests for categorical variables, one-way ANOVAs and the Tukey post-hoc tests for normally distributed metric variables and Kruskal-Wallis tests for skewed metric variables. 
The medians and interquartile ranges (IQR) of the timing of spontaneous rupture of the membranes (SROM), the timing of interventions, labour duration and the durations of the first and second stages of labour were computed with Kaplan-Meier estimates. Data concerning the time span between SROM or interventions and birth, overall labour duration and the durations of the first and second stages was treated as right-censored in the case of c-section or vaginal operative delivery (for the first stage of labour only in the case of c-section). By contrast, the durations between onset of labour and SROM or interventions were considered as non-censored. Kaplan-Meier survival curves (Bland \& Altman 1998, Sedgwick 2014) were compared either with the log rank test or with the Wilcoxon test, depending on the sensitivity region of the test and the differences in the shapes of the Kaplan-Meier curves.

Multivariable analyses were performed using shared frailty Cox regression models in order to take into account the variability between the locations (Gutierrez 2002, Bossfeld et al. 2007, Sedgwick 2013). Dependent variables of the models were labour duration and the durations of the first and second stages of labour respectively. Crude associations were assessed between the outcome variables and potential predictors (maternal age, health insurance, no risk factor in medical history, obesity, diabetes, gestational diabetes, induction, cervical dilatation at admission, meconium-stained liquor, rupture of the membranes, sex of the baby, birth weight, episiotomy (not for the first stage of labour), the duration of the first stage of labour (only for the model of the duration of the second stage of labour) and the type of documentation) with log rank testing for categorical variables and bivariable Cox regression models for metric variables. Variables were included in the main effect model if $p<0.25$, according to the model-building strategies of Hosmer and Lemeshow (2000). The time-dependent covariates (oxytocin, epidural analgesia and opioids) were included with episode splitting in order to avoid the time at risk before interventions occurred being taken into account (Shintani et al. 2009). If interventions occurred before the time interval of interest, this was taken into account in the models. Stepwise backward elimination was performed in the multivariable model (based on Likelihood Ratio Tests $\mathrm{p}<0.05$ ). It was decided to retain maternal age and birth weight in the model, as these are known from previous studies to be valid predictors (Albers 1999, Zhang et al. 2002). The type of documentation was retained in the model as well. Interactions were tested between the group variable and the 
time dependent variables and between the time dependent variables themselves. Interactions with $p<0.10$ were included in the full effects model but were eliminated again in the backward selection process if $p>0.05$.

P-values $<0.05$ were considered to be statistically significant and statistical analyses were conducted with Stata 13 (StataCorp, College Town, US).

\section{Findings}

\section{Baseline and perinatal characteristics}

Multiparous women with previous c-section gave birth at 24 of the 47 locations and the number of participants at each location ranged between 1 and 40 (Table 1). There was no statistically significant difference compared to primiparous women (45 out of 47 sites, range $=1-309, p=0.439$ ) or multiparous with a previous vaginal birth (42 out of 47 sites, range $1-178, p=0.253$ ).

The multiparae with pVBAC were significantly older than the primiparae (31.55 vs $27.97 \mathrm{yrs}, p<0.001$ ) but the same age as the multiparae planning a second vaginal birth ( 31.55 vs $30.74 \mathrm{yrs}, p=0.104$ ). Similar percentages of women in each of the study groups had private insurance or complementary private insurance with a senior medical consultant attending birth $(p=0.244)$. The proportion of women who were risk-factor free was highest among multiparae with pVBAC, the difference being significant as against other multiparae ( 67.77 vs $58.92 \%, p=0.016)$, but not significant as against primiparae ( 67.77 vs $62.21 \%, p=0.113$ ). Obesity $(p=0.459)$, diabetes $(p=0.407)$ and gestational diabetes in history $(p=0.282)$ did not differ significantly between the study groups.

The number of women whose labour, whether electively or because of indications, was induced either with oxytocin, prostaglandin, amniotomy, misoprostol or castor oil, differed significantly overall between the subgroups $(p=0.006)$ : the difference was not significant as between multiparae with pVBAC and primiparae (31.28 vs $29.06 \%$, $p=0.501$ ), but was significant as between multiparae with $p V B A C$ and multiparae with second vaginal birth ( 31.28 vs $24.19 \%, p=0.030$ ). Median cervical dilatation at admission did not differ significantly between the subgroups (multiparae with pVBAC: $2.00 \mathrm{~cm}$, primiparae: $2.00 \mathrm{~cm}$, other multiparae: $3.00 \mathrm{~cm}, \mathrm{p}=0.513$ ) and meconium- 
stained liquor occurred in similar frequencies $(\mathrm{p}=0.332)$. The frequency with which multiparae with pVBAC had spontaneous rupture of the membranes (SROM) before onset of labour was similar to that in primiparae (23.92 vs $25.69 \%, \mathrm{p}=0.578)$ but significantly higher as compared to other multiparae (23.92 vs $16.62 \%, p=0.011$ ). Amniotomy before onset of labour was not performed in multiparae with PVBAC and also only rarely in the other subgroups ( $p=0.274)$. Intrapartal SROM occurred more often in multiparae with pVBAC $(43.06 \%)$ than in primiparae $(38.41 \%)$ or other multiparae $(40.38 \%)$, but the difference was not significant $(\mathrm{p}=0.300)$. Amniotomy during labour was performed with similar frequency in multiparae with PVBAC and primiparae (33.01 vs $34.67 \%, p=0.633$ ), but significantly less often in multiparae with pVBAC than in other multiparae (33.01 vs $41.78 \%, p=0.018$ ).

Multiparae with first pVBAC (48.82\% in total and $42.65 \%$ during labour) received oxytocin significantly less often than primiparae $(56.95 \%$ in total with $\mathrm{p}=0.024$ and $53.54 \%$ during labour with $\mathrm{p}=0.003$ ) but significantly more often than multiparae women with second vaginal birth $(31.94 \%$ in total and $27.15 \%$ during labour, both differences $\mathrm{p}<0.001$ ). The frequency of epidural analgesia also differed significantly overall between the subsamples $(\mathrm{p}<0.001)$, being administered most often in multiparae with pVBAC (36.02\% in total, $35.07 \%$ during labour) as compared to primiparae (34.65\% in total, $33.90 \%$ during labour) and other multiparae (14.27\% in total, $13.84 \%$ during labour). However, in the comparisons of the individual subgroups the difference was significant only as between multiparae with pVBAC and other multiparae $(p<0.001)$ and not as between multiparae with pVBAC and primiparae (total $p=0.691$, during labour $p=0.734$ ). The administration of opioids, either pethidine, meptazinol or pentazocine, also differed between the subsamples ( $p<0.001)$. Multiparae with pVBAC $(43.13 \%$ in total, $41.23 \%$ during labour) received opioids slightly but not significantly less often than primiparae $(48.91 \%$ in total with $\mathrm{p}=0.111$ and $47.10 \%$ during labour with $\mathrm{p}=0.105$ ) but significantly more often than other multiparae $(28.98 \%$ in total and $28.11 \%$ during labour, $p<0.001)$. The proportions of multiparous women planning a first VBAC and of primiparae who did not have either amniotomy, oxytocin, epidural or opioids during labour were similar (16.59 vs $13.57 \%, p=0.229$ ); there was however a significant difference between multiparae with pVBAC and other multiparae in this respect (16.59 vs $28.55 \%$, $p<0.001)$. 
The frequency with which multiparae who actually achieved their first VBAC received episiotomies was similar to that for primiparae (48.63 vs $50.99 \%, p=0.586$ ) but significantly higher than that for multiparae with second vaginal birth (48.63 vs $19.98 \%, p<0.001)$. The birth weights of multiparae with pVBAC did not differ significantly from those of primiparae $(p=0.206)$ and other multiparae $(p=0.154)$, and neither did the sex of neonates $(p=0.936)$. However, there were highly significant differences in the modes of birth between multiparae with pVBAC and primiparae $(p<0.001)$ and between multiparae with pVBAC and other multiparae $(p<0.001)$. Multiparae with pVBAC had a significantly lower proportion of vaginal births in comparison to both primiparae $(69.19$ vs $83.40 \%, p<0.001)$ and other multiparae (69.19 vs $98.82 \%, p<0.001)$, and consequently the highest c-section rate of the subsamples ( 30.81 vs $16.60 \%$ for primiparae and $4.18 \%$ for other multiparae).

\section{The timing of intrapartal SROM and interventions}

Spontaneous rupture of the membranes (SROM) for multiparous women with first pVBAC occurred at a median time of 2.67 hours after onset of labour and was not significantly earlier than the timing of SROM for primiparous women (3.42 hrs, $\mathrm{p}=0.112$, Table 2 ) or multiparous women planning a second vaginal birth (2.67 hrs, $p=0.481$ ). A significant difference was found between the subsamples regarding the time between SROM and birth $(\mathrm{p}<0.001)$, with not significantly shorter median durations for multiparae with pVBAC than for primiparae (3.17 vs $3.53 \mathrm{hrs}, \mathrm{p}=0.762$ ) but significantly longer durations for multiparae with pVBAC than for other multiparae (3.17 vs 0.88 hrs, $p<0.001)$.

Amniotomy for multiparae with pVBAC was performed at a median time of 5.50 hours after onset of labour. This time span was slightly but not significantly shorter than that for primiparae (5.50 vs $5.83 \mathrm{hrs}, \mathrm{p}=0.198$ ) and significantly longer than that for other multiparae (5.50 vs $3.93 \mathrm{hrs}, \mathrm{p}<0.001$ ). The median duration from amniotomy to birth also differed between the subgroups $(p<0.001)$ with a non-significant difference between multiparae with pVBAC and primiparae (3.25 vs $2.25 \mathrm{hrs}, \mathrm{p}=0.162$ ) but a significant difference between multiparae with pVBAC and other multiparae (3.25 vs 0.60 hrs, $\mathrm{p}<0.001)$.

Oxytocin during labour for multiparae with pVBAC was administered at a median time of 5.75 hours after onset of labour, which was earlier, though not significantly so, than 
for primiparae (5.75 vs $6.00 \mathrm{hrs}, \mathrm{p}=0.596$ ), but significantly later compared to other multiparae (5.75 vs $4.25 \mathrm{hrs}, \mathrm{p}<0.001)$. The median duration from first intrapartal oxytocin administration to birth was 2.85 hours for multiparae with pVBAC and was not significantly shorter than the duration for primiparae (2.85 vs $3.18 \mathrm{hrs}, \mathrm{p}=0.645$ ) but significantly longer than the duration for other multiparae (2.85 vs $1.37 \mathrm{hrs}$, $p<0.001$ ).

Epidural analgesia for multiparae with pVBAC was administered at a median time of 4.00 hours after onset of labour, which was slightly but not significantly earlier than for primiparae (4.00 vs $4.67 \mathrm{hrs}, \mathrm{p}=0.416$ ) but significantly later than for other multiparae (4.00 vs $3.50 \mathrm{hrs}, \mathrm{p}=0.009$ ). The median duration between epidural and birth for multiparae with pVBAC was similar to that for primiparae (5.38 vs $5.17 \mathrm{hrs}$, $\mathrm{p}=0.315$ ) but significantly longer than that for other multiparae (5.38 vs $3.05 \mathrm{hrs,}$ $\mathrm{p}<0.001)$.

Opioids during labour were given to multiparae with pVBAC after a median time of 3.83 hours; this time interval was comparable to that for primiparae (3.83 vs $3.78 \mathrm{hrs}$, $p=0.851)$ but significantly longer than that for other multiparae (3.83 vs. 2.75 hrs, $p=0.026$ ). There was no significant difference as between multiparae with pVBAC and primiparae regarding the median duration between opioid administration and birth (4.55 vs $3.67 \mathrm{hrs}, \mathrm{p}=0.811$ ), but as between multiparae with pVBAC and other multiparae the difference was highly significant (4.55 vs $1.43 \mathrm{hrs}, \mathrm{p}<0.001)$.

The intervention-free interval for multiparae with pVBAC lasted $3.67 \mathrm{hrs}$; this was not significantly shorter than for primiparae $(3.80 \mathrm{hrs}, \mathrm{p}=0.375)$ but significantly longer than for other multiparae (3.08 hrs, $\mathrm{p}=0.015)$. The median duration between the first intervention and birth was similar in multiparae with pVBAC and primiparae (4.52 vs $4.12 \mathrm{hrs}, \mathrm{p}=0.550$ ) but differed significantly as between multiparae with pVBAC and other multiparae (4.52 vs $1.37 \mathrm{hrs}, \mathrm{p}<0.001)$.

Overall labour duration and the durations of the first and second stages

The multivariable shared frailty Cox regression model revealed no statistically significant difference in durations between onset of labour and birth as between multiparous women with previous c-section and primiparous women (8.83 vs 8.57 hrs, $\mathrm{HR}=0.998,95 \% \mathrm{Cl}=0.830-1.201, \mathrm{p}=0.987$, Table 3, Figure 1). In contrast, 
compared to multiparae with a second vaginal birth multiparae with first pVBAC had a significant longer labour duration (8.83 vs $4.63 \mathrm{hrs}, \mathrm{HR}=0.319,95 \% \mathrm{Cl}=0.265-0.385$, $p<0.001)$. There was strong evidence for heterogeneity between study locations (theta $=0.302, p<0.001)$.

The multivariable analyses confirmed no statistically significant difference in the duration of the first stage of labour for multiparae with pVBAC as compared to primiparae (7.42 vs $7.00 \mathrm{hrs}, \mathrm{HR}=0.916,95 \% \mathrm{Cl}=0.774-1.083, \mathrm{p}=0.303$, Table 3, Figure 2). Compared to other multiparae, however, multiparae with pVBAC had a significantly longer first stage of labour (7.42 vs 4.25 hrs, HR=0.402, 95\% Cl=0.339$0.478, p<0.001)$. Again, there was strong evidence for heterogeneity between study locations (theta $=0.233, p<0.001$ ).

In contrast to the comparisons of overall labour duration and the duration of first stage of labour, the multivariable shared frailty Cox regression model revealed that the second stage of labour was shorter for multiparae with pVBAC than for primiparae (0.55 vs $0.77 \mathrm{hrs}, \mathrm{HR}=1.341,95 \% \mathrm{Cl}=1.049-1.714, \mathrm{p}=0.019$, Table 3, Figure 3). Compared to other multiparae however, multiparae with pVBAC had a longer second stage of labour ( 0.55 vs 0.22 hrs, $\mathrm{HR}=0.334,95 \% \mathrm{Cl}=0.262-0.426$, $p<0.001)$. There was also strong evidence for heterogeneity between study locations, which however was minimal (theta=0.035, $\mathrm{p}<0.001$ ).

\section{Discussion}

This was the first study investigating the timing of SROM and of interventions for multiparous women planning a first VBAC and comparing them with primiparous women and multiparous women planning a second vaginal birth. Labour characteristics of multiparae with pVBAC strongly resembled those of primiparae for most parameters but differed significantly from those of other multiparae. However, there were also obvious relevant differences between multiparae with pVBAC and primiparae: multiparae with pVBAC were older, received oxytocin less often, gave birth vaginally significantly less often and had a shorter second stage of labour.

\section{Baseline and perinatal characteristics}

The similarity in age between multiparous women with first pVBAC and multiparous women with second vaginal birth, and the difference to primiparous women, were 
expected and naturally caused by the fact that women of both multiparae subgroups were expecting their second child. Multiparae with pVBAC had the highest rate of medical histories containing no risk factors. An explanation may be that in a country like Germany with high c-section and low VBAC rates (Euro-Peristat 2010, Gross et al. 2015), women with a previous c-section and additional risk factors are more often counselled to have an elective c-section in their subsequent pregnancies than those in the other subgroups.

Induction and labour augmentation with oxytocin have been found to be associated with increased rates of uterine rupture during VBAC (Dekker at al. 2010, Guise et al. 2010), which could explain the significantly lower rates for multiparae with pVBAC as compared to primiparae in the current study. This is congruent with guidelines which recommend that oxytocin should be administered with caution to women with pVBAC because of the increased risk of uterine rupture (DGGG 2010b, RCOG 2007). The rate of $69.19 \%$ of successful vaginal births after previous c-section corresponded to the range of rates found in other studies (60-85\%, Balachandran et al. 2014, Knight et al. 2014, Tessmer-Tuck et al. 2014).

\section{Timing of SROM and interventions and the duration of labour and its phases}

Regarding the timing of SROM and interventions, multiparous women with first pVBAC were similar to primiparous women for all the intervals analysed but differed significantly from multiparous women with second vaginal birth. This can be explained by the shorter overall labour duration of other multiparae, which obviously shortened the time intervals between onset of labour and events or interventions as well as birth. The differences between primiparae and multiparae have been investigated before (Petersen et al. 2011), but no previous study has investigated these aspects for multiparae with pVBAC.

Labour duration from the onset of labour until birth and the duration of the first stage of labour were very similar as between multiparae with pVBAC and primiparae. The similar first stages of labour found in the current study confirmed the findings of Graseck et al. (2012) and Harlass \& Duff (1990), but not those of Faranesh \& Salim (2011), who found a shorter active phase of labour in multiparae with pVBAC as compared to primiparae. However, the current study investigated the duration of the first stage of labour starting from the onset of labour as defined by the midwife in 
terms of regular or irregular contraction associated with cervical dilatation, and not only the active phase as Faranesh \& Salim did (2011). First stage of labour can be subdivided into a latent and an active phase, which is relevant for the assessment of delay in labour progression (Friedman 1955, Zhang et al. 2010, NICE 2014). However, there is no clearly defined cut off point (Zhang et al. 2010, NICE 2014), what makes comparison of phases difficult. The different results regarding the comparison of the duration of first stage of labour may arise from the varying definitions of onset of labour (Hanley et al., submitted for publication) and therefore from differences in the time interval investigated. Different statistical methods or the relatively small sample size of women with pVBAC with risk of imprecise results also have to be considered as potential reasons. By contrast, the shorter second stage of labour in multiparae with pVBAC as compared to primiparae confirmed the findings of Faranesh \& Salim (2011) using larger samples and time-to-event analysis. A shorter second stage of labour for multiparae with pVBAC was not to be expected and cannot be explained, because none of the women with pVBAC had previously experienced a completed second stage. However, this finding suggests that a distinction has to be made also between multiparae with PVBAC and primiparae, and not only between multiparae with pVBAC and other multiparae. Further research is needed to confirm these findings in larger samples of multiparous women with a previous c-section.

\section{Implication for midwifery practice}

Knowledge about the labour patterns of multiparous with first pVBAC may suggest how to improve intrapartum management, which is relevant for a safe and successful VBAC (Scott 2014). The similarities in frequencies and timings of events and interventions as between multiparae with pVBAC and primiparae and the differences as compared to other multiparae indicate a need to beware of preconceived expectations with regard to labour progression and to exercise patience, especially during the first stage of labour. The shorter second stage of labour might be a relevant aspect for antenatal and intrapartum midwifery care. The area of support for women with a previous c-section in deciding on the mode of birth in a subsequent pregnancy is a challenging one, and there is limited evidence as to how far decision support can bring about an increase in rates of vaginal births (Horey et al. 2013). King et al. (2015) recommend informing women with a previous c-section not only 
about the benefits and risks of VBAC and elective c-section but also about the high likelihood of a successful VBAC. The information that the second stage of labour of multiparae with pVBAC might be shorter as compared to primiparae could be a further factor increasing the motivation for a trial of labour after a c-section. Midwives may use this information in antenatal counselling. Such knowledge regarding a shorter second stage of labour of multiparae with pVBAC as compared to primiparae might also be useful for intrapartum counselling, support and motivation. However, further research in lager samples is needed to confirm these findings.

\section{Strengths and limitations}

A strength of the ProGeb study was the total sample size of 3,963 participants, of whom only 724 multiparaous women giving birth for at least the third time had to be excluded, so that 3,239 participants could be included in this secondary analysis. Furthermore, the documentation of the timing of labour onset, birth, SROM and interventions was done with minute precision. However, the study had its limitations in that it included only 211 multiparous women with a previous c-section planning their second childbirth as a VBAC. The small sample size of this subgroup makes generalisation of the findings questionable. Using prospective as well as retrospective data could be source of reporting bias. This aspect was considered in the regression model as a possible confounder. The inclusion of late preterm births between 34 and 37 gestational weeks could be questioned because of lower birth weights. However labour management of these births does not differ from the one at term (DGGG 2006, DGGG 2012). In order to account for this, birth weight was included in the regression models as a possible confounder. Further limitations were the high intervention rates making it questionable if the findings of this study are generalisable to settings with lower rates. Available national and regional figures from 2005 and 2014 however show comparably high intervention rates (epidural analgesia 18-44\%; induction 22-25\%, labour augmentation 32\%, episiotomy 23-35\%) (ZQ 2006, Euro-Peristat 2013, Aqua 2015). Women with emergency c-section before rupture of the membranes were considered as receiving amniotomy, which enhanced amniotomy rates. Further weaknesses were that no indications for the first c-section were reported and no information was available with regard to the stage of cervical dilatation at which the c-section was performed. Additionally, the multicentre 
characteristics of the study may have involved a lack of uniformity in intrapartum care.

Strengths of this secondary analysis were on the one hand the shared frailty Cox regression models, which took account of the variability of the locations; and on the other hand the fact that multivariable analyses were done with the dependent variables labour duration and the durations of the first and second stages of labour, thus taking into account the varying dynamics of the different labour phases.

Interventions occurring during the relevant period were included as time-varying covariates, and interventions before the time interval of interest were also taken into account. The different timings of interventions during labour could therefore be taken into account in the regression models. This maximized consideration of the dynamic nature of labour for childbirth, and was something that had not been done in previous longitudinal analyses of labour durations.

\section{Conclusion}

The differences in labour patterns between multiparous women with previous csection on the one hand primiparous and secundiparous women without previous csection on the other suggest that multiparae with pVBAC should be considered as a distinct group of birthing women. Expectations regarding labour progression and the timing of events and interventions during the first stage of labour should probably for the most part be similar to those for primiparae. However, the significantly shorter second stage of labour of multiparae with pVBAC as compared to primiparae, was a surprising finding of the current study and cannot be explained. Pregnant women with a previous c-section might be motivated to undergo a trial of labour if they know that the second stage of labour could be shorter as compared to primiparae. 


\section{List of abbreviations}

primiparae

other multiparae

multiparae with pVBAC

c-section

\section{ERCS}

VBAC

pVBAC

SROM

ARM

IQR

HR

$\mathrm{Cl}$
Primiparous women

Multiparous women planning their second vaginal birth

Multiparous women with first planned vaginal birth after one previous caesarean section

Caesarean section

Elective repeat caesarean section

Vaginal birth after caesarean section

Planned vaginal birth after caesarean section

Spontaneous rupture of the membranes

Artificial rupture of the membranes

Interquartile range

Hazard ratio

Confidence interval 


\section{References}

Albers, L.L., Schiff, M. \& Gorwoda, J.G., 1996. The length of active labor in normal pregnancies. Obstetrics and gynecology 87, 355-359.

Albers, L.L., 1999. The duration of labor in healthy women. Journal of perinatology : official journal of the California Perinatal Association 19, 114-119.

American College of Obstetricians and Gynecologists (ACOG, College), Society for Maternal-Fetal Medicine, Caughey, A.B. et al., 2014. Safe prevention of the primary cesarean delivery. American Journal of Obstetrics and Gynecology 210, 179-193.

AQUA- Institut für angewandte Qualitätsförderung und Forschung im Gesundheitswesen (AQUA), 16/1- Geburtshilfe, Qualitätsindikatoren, Bundesauswertung zum Verfahrensjahr 2014, (2015)

(https://www.sqg.de/downloads/Bundesauswertungen/2014/bu_Gesamt_16N1 GEBH_2014.pdf)

Arulkumaran, S., Gibb, D.M., Lun, K.C et al., 1984. The effect of parity on uterine activity in labour. British journal of obstetrics and gynaecology 91, 843-848.

Balachandran, L., Vaswani, P.R. \& Mogotlane, R., 2014. Pregnancy outcome in women with previous one cesarean section. Journal of clinical and diagnostic research : JCDR 8, 99-102.

Bland, J.M. \& Altman, D.G., 1998. Survival probabilities (the Kaplan-Meier method). BMJ (Clinical research ed.) 317, pp. 1572.

Blossfeld, H.P., Golsh, K., \& Rohwer, G., 2007. Event history analysis with Stata. Mahwah. NJ: Erlbaum.

Cheng, Y.W., Eden, K.B., Marshall, N. et al., 2011. Delivery after prior cesarean: maternal morbidity and mortality. Clinics in perinatology 38, 297-309.

Dekker, G.A., Chan, A., Luke, C.G. et al., 2010. Risk of uterine rupture in Australian women attempting vaginal birth after one prior caesarean section: a retrospective population-based cohort study. BJOG : an international journal of obstetrics and gynaecology 117, 1358-1365.

EURO-PERISTAT, 2013. European Perinatal Health Report, Health and Care of Pregnant Women and Babies in Europe in 2010.

(http://www.europeristat.com/reports/european-perinatal-health-report-2010.html)

Faranesh, R. \& Salim, R., 2011. Labor progress among women attempting a trial of labor after cesarean. Do they have their own rules?. Acta Obstetricia et Gynecologica Scandinavica 90, 1386-1392.

Fawsitt, C.G., Bourke, J., Greene, R.A. et al., 2013. At what price? A costeffectiveness analysis comparing trial of labour after previous caesarean versus elective repeat caesarean delivery. PloS one 8, e58577. 
Friedman, E.A., 1955. Primigravid labor; a graphicostatistical analysis, Obstetrics and gynecology, vol. 6 , no. 6, pp. 567-589.

German Society of Obstetrics and Gynaecology (DGGG), 2006. Procedure with premature rupture of the membranes, AWMF guideline Nr. 015/029.

(http://www.awmf.org/uploads/tx_szleitlinien/015-

029_S1_Empfehlungen_zum_Vorgehen_beim_vorzeitigen_Blasensprung_062006_06-2011_01.pdf)

German Society of Obstetrics and Gynaecology (DGGG), 2010a. Pre- and Peripartum Care in Women with Status Post Caesarean Section.

(http://www.dggg.de/leitlinienstellungnahmen/archivierte-leitlinien/federfuehrendeleitlinien-der-dggg/)

German Society of Obstetrics and Gynaecology (DGGG), 2010b. Tocolytics to prevent preterm birth, AWMF guideline Nr. 015/025.

(http://www.dggg.de/leitlinienstellungnahmen/archivierte-leitlinien/federfuehrendeleitlinien-der-dggg/)

German Society of Obstetrics and Gynaecology (DGGG), 2012. Application of the CTG during pregnancy and birth, AWMF guideline Nr. 015/036.

(http://www.awmf.org/uploads/tx_szleitlinien/015-

036I_S1_CTG_Schwangerschaft_Geburt_2014-06.pdf)

Grantz, K.L., Gonzalez-Quintero, V., Troendle, J. et al., 2015. Labor patterns in women attempting vaginal birth after cesarean with normal neonatal outcomes. American Journal of Obstetrics and Gynecology, .

Graseck, A.S., Odibo, A.O., Tuuli, M. et al., 2012. Normal first stage of labor in women undergoing trial of labor after cesarean delivery. Obstetrics and gynecology 119, 732-736.

Gross, M.M., Schwarz, Ch., Burian, R.A., et al., 2007. Midwifery teams differ in their opinions regarding study participation. Birth Issues 15, 77-82.

Gross, M.M., Burian, R.A., Fromke, C., et al., 2009. Onset of labour: women's experiences and midwives' assessments in relation to first stage of labour. Archives of Gynecology and Obstetrics 280, 899-905.

Gross, M.M., Petersen, A., Hille, U. \& Hillemanns, P., 2010. Association between women's self-diagnosis of labor and labor duration after admission. Journal of perinatal medicine 38 , 33-38.

Gross, M.M., Froemke, C. \& Hecker, H., 2014. The timing of amniotomy, oxytocin and neuraxial analgesia and its association with labour duration and mode of birth. Archives of Gynecology and Obstetrics 289, 41-48.

Gross, M.M., Matterne, A., Berlage, S. et al., 2015. Interinstitutional variations in mode of birth after a previous caesarean section: a cross-sectional study in six German hospitals. Journal of perinatal medicine 43, 177-184. 
Guise, J.M., Eden, K., Emeis, C. et al., 2010. Vaginal birth after cesarean: new insights. Evidence report/technology assessment 191, 1-397.

Gutierrez, R.G., 2002. Parametric frailty and shared frailty survival models. The Stata Journal 2, 22-44.

Hanley, G.. et al..Diagnosing onset of labour: A systematic review of definitions in the research literature. Submitted for publication.

Harlass, F.E. \& Duff, P., 1990. The duration of labor in primiparas undergoing vaginal birth after cesarean delivery. Obstetrics and gynecology 75, 45-47.

Horey, D., Kealy, M., Davey, M.A. et al., 2013. Interventions for supporting pregnant women's decision-making about mode of birth after a caesarean. The Cochrane database of systematic reviews 7, CD010041.

Hosmer, D.W. \& Lemeshow, S., 2000. Chapter 4. Model-Building Strategies and Methods for Logistic Regression. In: Hosmer, D.W. \& Lemeshow, S., Applied Logistic Regression, Second Edition, John Wiley and Sons, INC.

Karlström, A., Lindgren, H. \& Hildingsson, I., 2013. Maternal and infant outcome after caesarean section without recorded medical indication: findings from a Swedish case-control study. BJOG : an international journal of obstetrics and gynaecology, 120, 479-86.

Kealy, M.A., Small, R.E. \& Liamputtong, P., 2010. Recovery after caesarean birth: a qualitative study of women's accounts in Victoria, Australia. BMC pregnancy and childbirth 10, 47-2393-10-47.

King, V.J., Fontaine, P.L., Atwood, L.A., et al., 2015. Clinical practice guideline executive summary: labor after cesarean/planned vaginal birth after cesarean. Annals of family medicine $13,80-81$.

Knight, H.E., Gurol-Urganci, I., van der Meulen, J.H. et al., 2014. Vaginal birth after caesarean section: a cohort study investigating factors associated with its uptake and success. BJOG: an international journal of obstetrics and gynaecology 121, 183-192.

Landon, M.B., Hauth, J.C., Leveno, K.J., et al., 2004. Maternal and perinatal outcomes associated with a trial of labor after prior cesarean delivery. The New England journal of medicine 351, 2581-2589.

Marshall, N.E., Fu, R. \& Guise, J.M., 2011. Impact of multiple cesarean deliveries on maternal morbidity: a systematic review. American Journal of Obstetrics and Gynecology 205, 262.e1-262.e8.

Nair, M., Soffer, K., Noor, N. et al., 2015. Selected maternal morbidities in women with a prior caesarean delivery planning vaginal birth or elective repeat caesarean section: a retrospective cohort analysis using data from the UK Obstetric Surveillance System. BMJ open 5, e007434-2014-007434. 
Palatnik, A. \& Grobman, W.A. 2015. Induction of labor versus expectant management for women with a prior cesarean delivery. American Journal of Obstetrics and Gynecology 212, 358.e1-358.e6.

Petersen, A., Ayerle, G.M. Fromke, C. et al., 2011. The timing of interventions during labour: descriptive results of a longitudinal study, Midwifery 27, e267-73.

Petersen, A., Penz, S.M. \& Gross, M.M., 2013a. Women's perception of the onset of labour and epidural analgesia: a prospective study, Midwifery 29, 284-293.

Petersen, A., Poetter, U. Michelsen, C. \& Gross, M.M. 2013b. The sequence of intrapartum interventions: a descriptive approach to the cascade of interventions, Archives of Gynecology and Obstetrics 288, 245-254.

Prick, B.W., Bijlenga, D., Jansen, A.J., et al., 2015. Determinants of health-related quality of life in the postpartum period after obstetric complications. European journal of obstetrics, gynecology, and reproductive biology 185, 88-95.

Regan, J., Keup, C., Wolfe, K., et al. 2015. Vaginal birth after cesarean success in high-risk women: a population-based study. Journal of perinatology: official journal of the California Perinatal Association 35, 252-257.

Regan, J., Thompson, A. \& DeFranco, E., 2013. The influence of mode of delivery on breastfeeding initiation in women with a prior cesarean delivery: a population-based study. Breastfeeding medicine: the official journal of the Academy of Breastfeeding Medicine 8, 181-186.

Royal College of Obstetrician and Gynaecologist (RCOG). 2007. Birth after previous caesarean birth.

(https://www.rcog.org.uk/globalassets/documents/guidelines/gtg4511022011.pdf)

Sabol, B., Denman, M.A. \& Guise, J.M. 2015. Vaginal Birth After Cesarean: An Effective Method to Reduce Cesarean. Clinical obstetrics and gynecology 58, 309319.

Scott, J.R., 2014. Intrapartum management of trial of labour after caesarean delivery: evidence and experience. BJOG: an international journal of obstetrics and gynaecology $121,157-162$.

Sedgwick, P., 2013. Cox proportional hazards regression, BMJ 374, f4919

Sedgwick, P., 2014. How to read a Kaplan-Meier survival plot, BMJ (Clinical research ed.) 349, g5608.

Shintani, A.K., Girard, T.D., Eden, S.K., et al., 2009. Immortal time bias in critical care research: application of time-varying Cox regression for observational cohort studies, Critical Care Medicine 37, 2939-2945.

Shorten, A. \& Shorten, B., 2012. The importance of mode of birth after previous cesarean: success, satisfaction, and postnatal health. Journal of midwifery \& women's health $57,126-132$. 
Smith, G.C., Pell, J.P., Cameron, A.D. \& Dobbie, R. et al., 2002. Risk of perinatal death associated with labor after previous cesarean delivery in uncomplicated term pregnancies. JAMA : the journal of the American Medical Association 287, 26842690.

Tessmer-Tuck, J.A., El-Nashar, S.A., Racek, A.R. et al., 2014. Predicting vaginal birth after cesarean section: a cohort study. Gynecologic and obstetric investigation $77,121-126$.

Vahratian, A., Hoffman, M.K., Troendle, J.F. \& Zhang, J., 2006. The impact of parity on course of labor in a contemporary population. Birth (Berkeley, Calif.) 33, 12-17.

Zhang, J., Troendle, J.F. \& Yancey, M.K., 2002. Reassessing the labor curve in nulliparous women. American Journal of Obstetrics and Gynecology 187, 824-828.

Zhang, J., Landy, H.J., Branch, D.W., et al., 2010. Contemporary patterns of spontaneous labor with normal neonatal outcomes. Obstetrics and gynecology 116, 1281-1287.

ZQ Centre for quality and management in the health system, 2006. Obstetric, Anual figures for 2005, Module 16/1. (https://www.aekn.de/zq-

home/projekte/perinatalerhebung/download-statistiken/ 
Tables "Labour characteristics pVBAC"

Table 1: Baseline and perinatal characteristics

\begin{tabular}{|c|c|c|c|c|}
\hline Variable & $\begin{array}{l}\text { Primiparae } \\
(\mathrm{n}=1879)\end{array}$ & $\begin{array}{l}\text { Multiparae 1st } \\
\text { pVBAC } \\
(n=211)\end{array}$ & $\begin{array}{l}\text { Multiparae } \\
\text { 2nd vaginal } \\
\text { birth } \\
(n=1149)\end{array}$ & p-value ${ }^{1}$ \\
\hline \multicolumn{5}{|l|}{ General information } \\
\hline $\begin{array}{l}\text { No. of locations/47 (range } n \text { of } \\
\text { births) }\end{array}$ & $45(1-309)$ & $24(1-40)$ & $42(1-178)$ & $p=0.047^{c}$ \\
\hline Retrosp. documentation, $\mathrm{n}(\%)^{2}$ & $1317(70.09)$ & $163(77.25)$ & $807(70.23)$ & $\mathrm{p}=0.090^{\mathrm{a}, \mathrm{b}}$ \\
\hline \multicolumn{5}{|c|}{ Socio-demographic and medical history related characteristics } \\
\hline Age in years; mean (min-max) & $27.97(14-46)$ & $31.55(18-45)$ & $30.74(18-45)$ & $\mathrm{p}<0.001^{\mathrm{a}, \mathrm{c}}$ \\
\hline Private insurance; $\mathrm{n}(\%)^{3}$ & $144(7.66)$ & $18(8.53)$ & $108(9.40)$ & $p=0.244$ \\
\hline No risk factor in history; $\mathrm{n}(\%)$ & $1169(62.21)$ & $143(67.77)$ & $677(58.92)$ & $\mathrm{p}=0.028^{\mathrm{b}}$ \\
\hline Obesity; n (\%) & $73(3.89)$ & $10(4.74)$ & $55(4.79)$ & $p=0.459$ \\
\hline Diabetes; n (\%) & $12(0.64)$ & $1(0.47)$ & $12(1.05)$ & $p=0.407$ \\
\hline Gestational diabetes; n (\%) & $59(3.14)$ & $11(5.21)$ & $38(3.31)$ & $p=0.282$ \\
\hline \multicolumn{5}{|l|}{ Perinatal characteristics } \\
\hline Induction of labour; n (\%) & $546(29.06)$ & $66(31.28)$ & $278(24.19)$ & $\mathrm{p}<0.006^{\mathrm{b}, \mathrm{c}}$ \\
\hline $\begin{array}{l}\text { Cervical dilation at admission in } \\
\mathrm{cm} \text {; median (IQR) }\end{array}$ & $\begin{array}{l}2.00 \\
(1.00-4.00)\end{array}$ & $\begin{array}{l}2.00 \\
(1.00-3.00)\end{array}$ & $\begin{array}{l}3.00 \\
(2.00-5.00)\end{array}$ & $\mathrm{p}=0.513$ \\
\hline Meconium-stained liquor; n (\%) & $217(11.55)$ & $31(14.69)$ & $128(11.14)$ & $p=0.332$ \\
\hline $\begin{array}{l}\text { Rupture of the membranes: } \\
\text { Prelabour SROM; n (\%) } \\
\text { Prelabour ARM; n (\%) } \\
\text { Intrapartal SROM; n (\%) } \\
\text { Intrapartal ARM; n (\%) }\end{array}$ & $\begin{array}{l}481(25.69) \\
23(1.23) \\
719(38.41) \\
649(34.41)\end{array}$ & $\begin{array}{l}50(23.92) \\
0(0.00) \\
90(43.06) \\
69(33.01)\end{array}$ & $\begin{array}{l}191(16.62) \\
14(1.22) \\
464(40.38) \\
480(41.78)\end{array}$ & $p<0.001^{b, c}$ \\
\hline Oxytocin; n (\%) & $1070(56.95)$ & $103(48.82)$ & 367 (31.94) & $\mathrm{p}<0.001^{\mathrm{a}, \mathrm{b}, \mathrm{c}}$ \\
\hline Epidural analgesia, n (\%) & $651(34.65)$ & $76(36.02)$ & $164(14.27)$ & $\mathrm{p}<0.001^{\mathrm{b}, \mathrm{c}}$ \\
\hline Opioids; n (\%) & $919(48.91)$ & $91(43.13)$ & $333(28.98)$ & $p<0.001^{b, c}$ \\
\hline Episiotomy; n (\%) & 799 (50.99) & $71(48.63)$ & $220(19.98)$ & $p<0.001^{b, c}$ \\
\hline $\begin{array}{l}\text { No intrapartal interventions; } \\
\mathrm{n}(\%)\end{array}$ & $255(13.57)$ & 35 (16.59) & $328(28.55)$ & $\mathrm{p}<0.001^{\mathrm{b}, \mathrm{c}}$ \\
\hline $\begin{array}{l}\text { Birth weight in g; mean } \\
\text { (min-max) }\end{array}$ & $\begin{array}{l}3407.71 \\
(1720-5370)\end{array}$ & $\begin{array}{l}3466.29 \\
(2060-4900)\end{array}$ & $\begin{array}{l}3532.10 \\
(1760-5240)\end{array}$ & $p<0.001^{c}$ \\
\hline Female sex; n (\%) & $918(48.88)$ & $105(49.76)$ & $557(48.48)$ & $p=0.936$ \\
\hline $\begin{array}{l}\text { Mode of birth: } \\
\text { Spontaneous; n (\%) } \\
\text { Vacuum; n (\%) }\end{array}$ & $\begin{array}{l}1366(72.70) \\
151(8.04)\end{array}$ & $\begin{array}{l}131(62.09) \\
12(5.69)\end{array}$ & $\begin{array}{l}1078(93.82) \\
19(1.65)\end{array}$ & $p<0.001^{a, b, c}$ \\
\hline
\end{tabular}


IQR=interquartile range; $S R O M=$ spontaneous rupture of the membranes; $A R M=a m n i o t o m y$

${ }^{1}$ Tukey post-hoc tests after ANOVA, Kruskal Wallis tests or chi squared tests

${ }^{2}$ Retrospective as opposed to prospective documentation

${ }^{3}$ Private insurance or complementary insurance with senior medical consultant in contrast to statutory insurance

${ }^{4}$ For vaginal births

${ }^{a}$ Significant difference between multiparae with first pVBAC and primiparae

${ }^{\mathrm{b}}$ Significant difference between multiparae with first pVBAC and multiparae with second vaginal birth

${ }^{c}$ Significant difference between primiparae and multiparae with second vaginal birth 
Table 2: Duration of labour and the timing of intrapartal SROM and interventions

\begin{tabular}{lllll}
\hline $\begin{array}{l}\text { Variable } \\
\text { Duration, frequency and } \\
\text { timing }\end{array}$ & $\begin{array}{l}\text { Primiparae } \\
(\mathrm{n}=1879)\end{array}$ & $\begin{array}{l}\text { Multiparae 1st } \\
\text { pVBAC } \\
(\mathrm{n}=211)\end{array}$ & $\begin{array}{l}\text { Multiparae 2nd } \\
\text { vaginal birth } \\
(\mathrm{n}=1149)\end{array}$ & $\mathrm{p}$-value \\
\hline $\begin{array}{l}\text { Onset of labour - birth, hrs; } \\
\text { median (IQR) }\end{array}$ & $8.57(5.60-13.42)$ & $8.83(5.35-16.55)$ & $4.63(2.85-7.05)$ & $\mathrm{p}<0.001^{\mathrm{b}, \mathrm{c}}$ \\
$\begin{array}{l}\text { First stage of labour, hrs; } \\
\text { median (IQR) }\end{array}$ & $7.00(4.50-10.50)$ & $7.42(4.42-12.50)$ & $4.25(2.60-6.50)$ & $\mathrm{p}<0.001^{\mathrm{b}, \mathrm{c}}$ \\
$\begin{array}{l}\text { Second stage of labour, hrs; } \\
\text { median (IQR) }\end{array}$ & $0.77(0.38-1.47)$ & $0.55(0.27-1.28)$ & $0.22(0.12-0.42)$ & $\mathrm{p}<0.001^{\mathrm{a}, \mathrm{b}, \mathrm{c}}$ \\
$\begin{array}{l}\text { Onset of labour- SROM, } \\
\text { hrs; median (IQR) }\end{array}$ & $3.42(1.00-6.63)$ & $2.67(0.48-5.83)$ & $2.67(0.83-5.08)$ & $\mathrm{p}<0.001^{\mathrm{c}}$ \\
$\begin{array}{l}\text { SROM - birth, hrs; } \\
\text { median (IQR) }\end{array}$ & $3.53(1.18-7.80)$ & $3.17(1.15-8.98)$ & $0.88(0.25-2.45)$ & $\mathrm{p}<0.001^{\mathrm{b}, \mathrm{c}}$ \\
$\begin{array}{l}\text { Onset of labour - ARM, hrs; } \\
\text { median (IQR) }\end{array}$ & $5.83(3.67-9.08)$ & $5.50(3.83-7.22)$ & $3.93(2.33-6.08)$ & $\mathrm{p}<0.001^{\mathrm{b}, \mathrm{c}}$ \\
$\begin{array}{l}\text { ARM - birth, hrs; median } \\
\text { (IQR) }\end{array}$ & $2.25(1.00-4.45)$ & $3.25(1.03-5.55)$ & $0.60(0.25-1.43)$ & $\mathrm{p}<0.001^{\mathrm{b}, \mathrm{b}}$ \\
$\begin{array}{l}\text { Onset of labour - oxytocin, } \\
\text { hrs; median (IQR) }\end{array}$ & $6.00(3.92-9.20)$ & $5.75(3.98-10.25)$ & $4.25(2.50-6.55)$ & $\mathrm{p}<0.001^{\mathrm{b}, \mathrm{c}}$ \\
$\begin{array}{l}\text { Oxytocin - birth hrs; } \\
\text { median (IQR) }\end{array}$ & $3.18(1.20-6.42)$ & $2.85(1.27-8.32)$ & $1.37(0.67-2.92)$ & $\mathrm{p}<0.001^{\mathrm{b}, \mathrm{c}}$ \\
$\begin{array}{l}\text { Onset of labour - epidural, } \\
\text { hrs; median (IQR) }\end{array}$ & $4.67(2.75-7.42)$ & $4.00(2.42-7.25)$ & $3.50(2.00-5.08)$ & $\mathrm{p}<0.001^{\mathrm{b}, \mathrm{c}}$ \\
$\begin{array}{l}\text { Epidural - birth, hrs; } \\
\text { median (IQR) }\end{array}$ & $5.17(3.45-8.42)$ & $5.38(3.90-14.22)$ & $3.05(1.75-4.53)$ & $\mathrm{p}<0.001^{\mathrm{b}, \mathrm{c}}$ \\
$\begin{array}{l}\text { Onset of labour - opioids, } \\
\text { hrs; median (IQR) }\end{array}$ & $3.78(2.00-6.67)$ & $3.83(1.75-6.00)$ & $2.75(1.62-5.33)$ & $\mathrm{p}<0.001^{\mathrm{b}, \mathrm{c}}$ \\
$\begin{array}{l}\text { Opioids - birth, hrs; } \\
\text { median (IQR) }\end{array}$ & $3.87(2.05-7.62)$ & $4.55(1.82-7.75)$ & $1.43(0.83-2.63)$ & $\mathrm{p}<0.001^{\mathrm{b}, \mathrm{c}}$ \\
$\begin{array}{l}\text { Onset of labour - first } \\
\text { intervention, hrs; } \\
\text { median (IQR) }\end{array}$ & $3.80(2.08-6.42)$ & $3.67(2.00-5.75)$ & $3.08(1.67-5.17)$ & $\mathrm{p}<0.001^{\mathrm{b}, \mathrm{c}}$ \\
$\begin{array}{l}\text { First intervention - birth, } \\
\text { hrs; median (IQR) }\end{array}$ & $4.12(1.98-7.62)$ & $4.52(1.75-7.75)$ & $1.37(0.58-2.70)$ & $\mathrm{p}<0.001^{\mathrm{b}, \mathrm{c}}$ \\
\hline
\end{tabular}

SROM=spontaneous rupture of the membranes, ARM=amniotomy

${ }^{a}$ Significant difference between multiparae with first pVBAC and primiparae

${ }^{\mathrm{b}}$ Significant difference between multiparae with first pVBAC and multiparae with second vaginal birth

${ }^{c}$ Significant difference between primiparae and multiparae with second vaginal birth 
Table 3: Adjusted shared frailty Cox regression models for overall labour duration and the durations of the first and second stages of labour

\begin{tabular}{llll}
\hline Time interval/comparison & Hazard ratio & $\mathbf{9 5 \%}$ Cl & p-value \\
\hline $\begin{array}{l}\text { Overall labour duration }{ }^{1}: \\
\text { Multiparae with first pVBAC with reference primiparae }\end{array}$ & 0.998 & $0.830-1.201$ & 0.987 \\
$\begin{array}{l}\text { Multiparae with first pVBAC with reference multiparae } \\
\text { with second vaginal birth }\end{array}$ & 0.319 & $0.265-0.385$ & $<0.001$ \\
\hline $\begin{array}{l}\text { First stage of labour }{ }^{2}: \\
\text { Multiparae with first pVBAC with reference primiparae }\end{array}$ & 0.916 & $0.774-1.083$ & 0.303 \\
$\begin{array}{l}\text { Multiparae with first pVBAC with reference multiparae } \\
\text { with second vaginal birth }\end{array}$ & 0.402 & $0.339-0.478$ & $<0.001$ \\
\hline $\begin{array}{l}\text { Second stage of labour }{ }^{3}: \\
\text { Multiparae with first pVBAC with reference primiparae }\end{array}$ & 1.341 & & \\
$\begin{array}{l}\text { Multiparae with first pVBAC with reference multiparae } \\
\text { with second vaginal birth }\end{array}$ & 0.334 & $0.262-0.426$ & $<0.001$ \\
\hline
\end{tabular}

${ }^{1}$ Adjusted for: maternal age, health insurance, no risk factor in history, induction, meconium-stained liquor, cervical dilatation at admission, birth weight, rupture of the membranes, timing of epidural, timing of opioid, interaction between the timing of epidural and the timing of opioids, type of documentation

${ }^{2}$ Adjusted for: maternal age, health insurance, no risk factor in history, induction, meconium stained liquor, cervical dilatation at admission, birth weight, rupture of the membranes, type of documentation

${ }^{3}$ Adjusted for: maternal age, cervical dilatation at admission, birth weight, episiotomy, rupture of the membranes, timing of oxytocin, timing of epidural, interaction between parity and timing of oxytocin, interaction between timing of oxytocin and timing of epidural, type of documentation 


\section{Figures "Labour characteristics of pVBAC"}

Figure 2: Kaplan-Meier curves for the first stage of labour

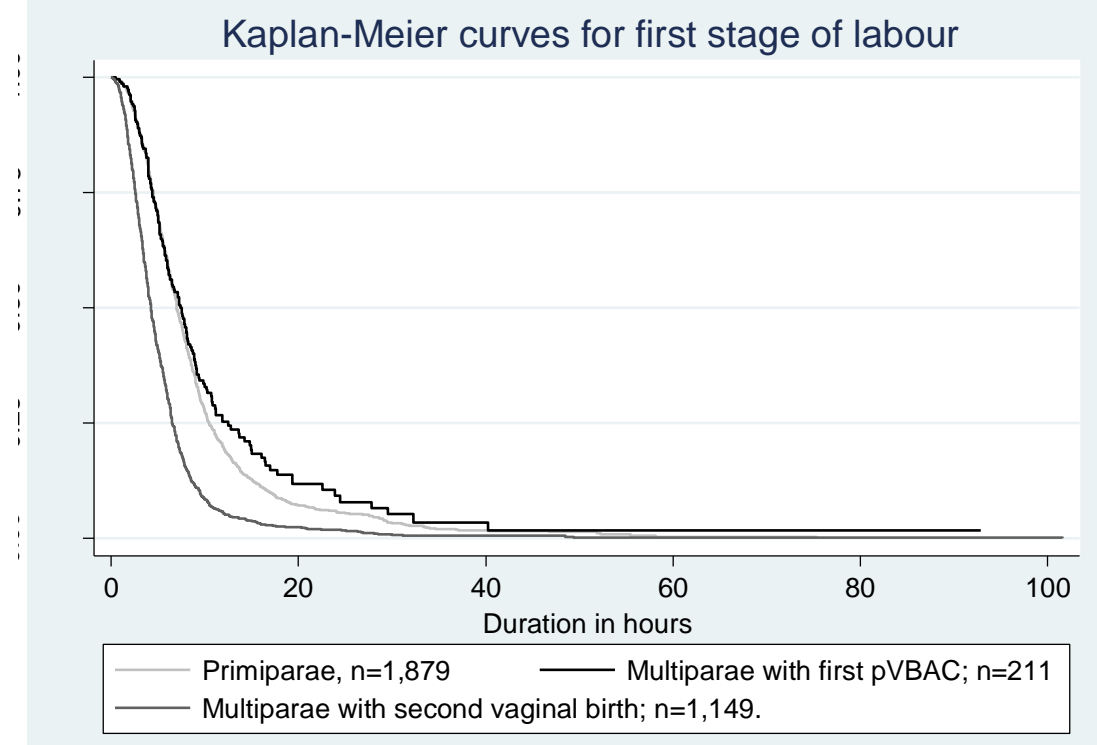

